
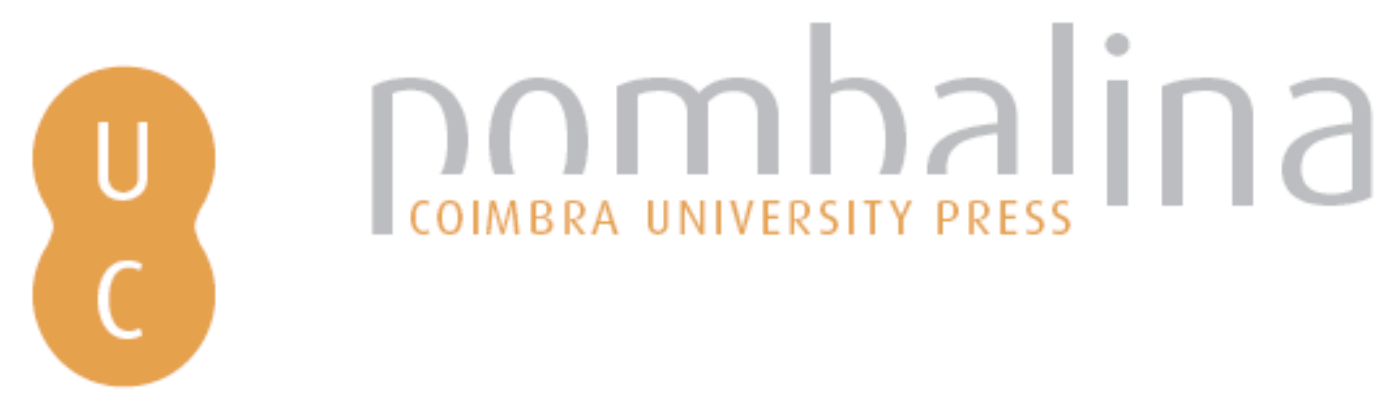

\title{
On the use of compact thermal cameras for quantitative wildfire monitoring
}

\begin{tabular}{|c|c|}
\hline Autor(es): & $\begin{array}{l}\text { Valero, Mario M.; Jimenez, Dan; Butler, Bret; Mata, Christian; Rios, Oriol; } \\
\text { Pastor, Elsa; Planas, Eulàlia }\end{array}$ \\
\hline Publicado por: & Imprensa da Universidade de Coimbra \\
\hline $\begin{array}{l}\text { URL } \\
\text { persistente: }\end{array}$ & URI:http://hdl.handle.net/10316.2/44636 \\
\hline DOI: & DOI:https://doi.org/10.14195/978-989-26-16-506_119 \\
\hline Accessed : & 26-Apr-2023 10:19:21 \\
\hline
\end{tabular}

A navegação consulta e descarregamento dos títulos inseridos nas Bibliotecas Digitais UC Digitalis, UC Pombalina e UC Impactum, pressupõem a aceitação plena e sem reservas dos Termos e Condições de Uso destas Bibliotecas Digitais, disponíveis em https://digitalis.uc.pt/pt-pt/termos.

Conforme exposto nos referidos Termos e Condições de Uso, o descarregamento de títulos de acesso restrito requer uma licença válida de autorização devendo o utilizador aceder ao(s) documento(s) a partir de um endereço de IP da instituição detentora da supramencionada licença.

Ao utilizador é apenas permitido o descarregamento para uso pessoal, pelo que o emprego do(s) título(s) descarregado(s) para outro fim, designadamente comercial, carece de autorização do respetivo autor ou editor da obra.

Na medida em que todas as obras da UC Digitalis se encontram protegidas pelo Código do Direito de Autor e Direitos Conexos e demais legislação aplicável, toda a cópia, parcial ou total, deste documento, nos casos em que é legalmente admitida, deverá conter ou fazer-se acompanhar por este aviso.

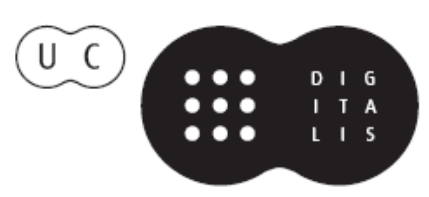




\section{ADVANCES IN}

\section{FOREST FIRE RESEARCH}

\section{8}

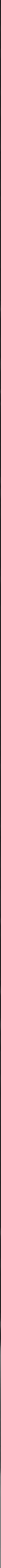




\title{
On the use of compact thermal cameras for quantitative wildfire monitoring
}

\author{
Mario M. Valero ${ }^{1 *}$; Dan Jimenez ${ }^{2}$; Bret Butler ${ }^{2}$; Christian Mata ${ }^{1}$; Oriol Rios ${ }^{1}$; Elsa Pastor ${ }^{1}$; Eulàlia \\ Planas $^{1}$ \\ ${ }^{1}$ Centre for Technological Risk Studies, Universitat Politècnica de Catalunya-BarcelonaTech. \\ Barcelona, Spain. \{mario.miguel.valero@upc.edu*\} \\ ${ }^{2}$ Fire Sciences Laboratory, Rocky Mountain Research Station, USDA Forest Service, Missoula, \\ $M T, U S A$
}

\begin{abstract}
In recent times, there have been significant developments in remote sensing techniques applied to forest fire research. In particular, infrared (IR) imagery has proved effective to measure variables such as rate of spread, fire radiative power and Byram's intensity. Remote sensing methodologies provide spatially explicit data in a cost-effective manner and reduce the need for intensive surveying campaigns. Concurrently, IR technology has seen remarkable maturing and thermal cameras have become increasingly light, compact and affordable. New models weigh only a few hundreds of grams, they have the size of a phone and they can be easily installed aboard remotely piloted aircraft (RPAS). Whereas these advances may be the base for powerful quantitative fire monitoring systems, there are some practical issues that need to be addressed before the full potential of this technology can be achieved. In this paper, we present our experience with two modern compact thermal cameras, and we explain how we overcame the difficulties we found. Two medium-scale experimental burns were recorded and computer vision algorithms were used to track the fire perimeter and measure its rate of spread (ROS). For performance reasons, one of the cameras encapsulated raw radiometric information in binary files with a non-standard proprietary video format. Adequate processing of this format was required to obtain brightness temperature distributions with a high temporal resolution (27 frames per second). On the other hand, the second camera stored IR frames as JPEG images with no radiometric information and with a low temporal resolution (approximately 1 frame per second, not constant). Additionally, this camera was operated from a small drone and significant jitter was present in the recorded video. To make data from the second camera usable, we applied video stabilization algorithms and we retrieved the exact time of acquisition of each frame from the metadata saved with each image. Ultimately, pre-processed IR data from both cameras was successfully used to detect the fire front, track the fire perimeter and compute rates of spread. All these tasks were performed automatically. Still, human interaction was required to georeference the imagery using ground control points. Georeferencing aerial imagery automatically remains one of the main challenges for the achievement of a fully automated fire monitoring system. Nevertheless, results obtained here were satisfactory. The algorithms for fire front detection, fire perimeter tracking and ROS estimation worked successfully, even when available data had significant limitations. The information retrieved from IR imagery through these algorithms can be further combined with other remote sensing products that provide details about fuel, weather and terrain. Moreover, observed data may be used to adjust data-driven fire spread simulators in real time so that they can produce accurate forecasts about the fire evolution, at least in the short term. These technological developments make important contributions towards the accomplishment of affordable, yet reliable, operational decision-support systems (DSS) that can be deployed during an emergency.
\end{abstract}

Keywords: Decision Support Systems, Fire Monitoring, Fire Segmentation, Remote Sensing, Thermal Infrared Cameras, Unmanned Aerial Vehicles

\section{Introduction}

Quantitative wildfire monitoring is essential for two reasons. On the one hand, to provide emergency response teams with meaningful, accurate information about the state of the fire during an incident. On the other, to study a number of aspects related to fire behavior. Extensive experimental 
campaigns have been conducted with the aim of improving scientific knowledge of wildfire dynamics, e.g. Clements et al. (2007, 2014), Cruz et al. (2010), Ottmar et al. (2016). Within the acquired datasets, spatially and temporally explicit measurements of fire radiant emission and fire rate of spread have been considered to be critical for the investigation of fire behavior and effects (O'Brien et al. 2016). Similarly, continuous surveillance of the fire perimeter and remote measurement of its rate of spread during a real emergency would greatly assist decision making. Current telecommunication systems and information management technologies support the combination of such measurements with other relevant data such as fuel properties, fuel spatial distribution, digital elevation models and updated weather variables. Furthermore, there exist fire spread simulators that can forecast the fire evolution in the short term. The availability of all this information in real time would notably increase the level of situational awareness in a scenario that can quickly become dangerous.

However, this technology-assisted decision-support context is incomplete at present. Real-time information available during a wildfire incident is, in the best case, limited to crew positions, weather data and discrete observations of the fire state. There is no continuous monitoring of the fire perimeter location, the active fire lines, their rate of spread or their burning intensity. Furthermore, operational fire spread simulators have insufficient accuracy to be relied on in a potentially dangerous scenario (Cruz and Alexander 2013). A proposed solution to the limited accuracy of operational fire spread simulators is the use of data assimilation techniques (Mandel et al. 2008; Rios et al. 2014, 2016; Rochoux et al. 2014, 2015), but this approach needs frequent, updated and spatially-explicit information about the fire evolution.

Thermal Infrared (TIR) imagery has proved to be a suitable technology to obtain continuous information about an active fire. Some variables that can be estimated remotely using IR cameras are the fire perimeter location, the rate of spread, the Fire Radiative Power (FRP) and Byram's fire intensity (Pérez et al. 2011; Paugam et al. 2013; Stow et al. 2014; Butler et al. 2016; Dickinson et al. 2016; Johnston et al. 2017). In this regard, our previous work contributed to automate the analysis of aerial TIR imagery through computer vision techniques (Valero et al. 2017, 2018). Algorithms of this type allow the automated acquisition of spatially explicit, high-frequency fire information, and they may be the base of a quantitative monitoring system with applicability to wildfire incident management and wildfire research. Furthermore, thermal infrared cameras, which had historically been expensive, complex and heavy, have experienced a notable decrease in size, weight and price, until the point of being suitable for installation aboard Remotely Piloted Aerial Systems (RPAS) and Unmanned Aerial Systems (UAS). RPAS and UAS have numerous advantages and a promising potential in forest fire management and research. Being able to use IR imagery acquired by these small aircraft would be a remarkable step forward towards the accomplishment of powerful, yet affordable, fire monitoring systems.

Nonetheless, to the best of our knowledge, all previous studies that successfully used infrared imagery to derive fire behavior information employed conventional thermal cameras (Plucinski and Pastor 2013; Paugam et al. 2013; Butler et al. 2016; O'Brien et al. 2016; Johnston et al. 2017; Valero et al. 2018). There have been very few attempts to use modern compact IR cameras to sense fire behavior, and there is a general concern in the scientific community about the image quality achievable by low-end IR cameras. Furthermore, some unsuccessful experiences have been reported when using RPAS, mainly due to difficulties in georeferencing the imagery and saturation of the IR sensors (Dickinson et al. 2016; Zajkowski et al. 2016).

In this work, we present a successful coupling of quantitative fire monitoring algorithms with compact, affordable IR cameras. Two camera models, from two different manufacturers, were tested in medium-scale experimental burns using dissimilar setups. An RPAS was successfully used in one of the experiments, and collected imagery was used to follow the fire perimeter evolution and to measure its rate of spread. Existing computer vision algorithms were adapted and additional preprocessing modules were developed to deal with the limitations of each camera. 


\section{Compact IR cameras}

Thermal infrared cameras have seen an outstanding development in the last few years, on both market ends. On the one hand, high-end devices that work at high speed and with high resolution are allowing unprecedented studies of fire behavior and characteristic fire structures at different scales (McAllister and Finney 2017; Miller et al. 2017). On the other, cameras with basic capabilities have become smaller, lighter and cheaper than ever.

Fire monitoring entails specific requirements such as a wide temperature measurement range to avoid sensor saturation and, at least, medium resolution so that fire behavior can be sensed from a distance that might go from a few meters to a few hundreds of meters. Until recently, these requisites prevented fire researchers from relying on low-end IR camera models. However, camera manufacturers have started to produce compact cameras that meet the needs of many wildfire studies. We had the opportunity to test two models from two known international manufacturers. The main specifications of the tested models are summarized in table 1.

Table 1 - Technical specifications of the two tested cameras

\begin{tabular}{c|ccccccc} 
Camera & $\begin{array}{c}\text { Commercial } \\
\text { Name }\end{array}$ & $\begin{array}{c}\text { Dimensions } \\
(\mathrm{mm})\end{array}$ & $\begin{array}{c}\text { Weight } \\
(\mathrm{g})\end{array}$ & $\begin{array}{c}\text { Image } \\
\text { Resolution } \\
(\text { pixels })\end{array}$ & $\begin{array}{c}\text { Spectral } \\
\text { range }(\mu \mathrm{m})\end{array}$ & $\begin{array}{c}\text { Temperature } \\
\text { measurement } \\
\text { range }{ }^{*}\left({ }^{\circ} \mathrm{C}\right)\end{array}$ & Output \\
\hline 1 & Optris PI 400 & $46 \times 56 \times 90$ & 320 & $382 \times 288$ & {$[7.5,13]$} & {$[200,1500]$} & $\begin{array}{c}\text { Radiometric video, } \\
\text { proprietary format }\end{array}$ \\
2 & $\begin{array}{c}\text { DJI Zenmuse } \\
\text { XT (developed } \\
\text { by FLIR) }\end{array}$ & $\begin{array}{c}103 \times 74 \times 102 \\
(\text { Gimbal } \\
\text { included })\end{array}$ & 270 & $640 \times 512$ & {$[7.5,13.5]$} & {$[-40,550]$} & $\begin{array}{c}\text { Individual JPEG } \\
\text { images, no radiometric } \\
\text { information }\end{array}$
\end{tabular}

*Manufacturers usually offer several calibration options for different temperature ranges. The values shown in this table correspond to the measurement ranges used during the tests described in this article.

The two IR cameras listed in table 1 have some characteristics in common. Both are compact and based on uncooled microbolometers. They both need a reduced amount of power to work and they cannot operate on their own but need to be connected to some kind of controlling hardware. The controller might be a laptop, a tablet or a single-board microcomputer. These characteristics make them especially convenient for portable field experimental setups and for installation aboard RPAS. In this study, camera 1 was connected to a laptop whereas camera 2 was operated from a drone through an on-board microcomputer.

Despite meeting the basic technical needs for large-scale fire monitoring (i.e. suitable temperature measurement range and sufficient resolution), these cameras entail significant limitations in the data processing workflow. Each manufacturer normally uses its own private software to operate their cameras and their own private format to store data. Raw IR data can afterwards be inspected only with their own software. Manufacturers' programs, provided with easy-to-use graphical user interfaces, are convenient for most industry clients. However, the use of non-standard formats and the lack of transparency in the camera control software constitute serious drawbacks for fire researchers, who usually need full access to the raw thermal data. Furthermore, there are other practical constraints when using these cameras in situations with limited resources, such as a drone or in the field. For instance, IR video files can easily become too large for modest systems, which usually implies restrictions in the recording frame rate. In the next sections, we discuss how these limitations affect quantitative fire monitoring algorithms and how they can be worked around.

\section{Experimental sites}

We tested our cameras in two medium-scale experimental burns. Test 1 was performed at the Tall Timbers Research Station in Tallahassee, FL, USA, in April 2017. Test 2 was conducted on The Nature Conservancy land next to Baxley, GA, USA, in January 2017. The cameras were used differently in 
each occasion. Test 1 was recorded with camera 1 from a fixed overhead position that provided an oblique view of the plot. In test 2, camera 2 was operated from a small RPAS hovering above the plot.

\subsection{Test 1: Fixed vantage point, off-nadir}

Test 1 was conducted in plot $\mathrm{C} 1$ of the Pebble Hill sites at Tall Timbers, which consisted of mixed southern rough/long leaf pine fuels. This plot was equipped with two highly-instrumented plots (HIPs) consisting of several radiometers, visual and thermal cameras. These items were geolocated and used as ground control points (GCPs) for imagery geocorrection. Furthermore, a thermal camera (camera 1 of this study) was installed on top of a boom lift situated at the south-east corner of the plot. Figure 1 shows the layout and some representative distances. Most of the GCPs were distinguishable in the IR video, but in different frames. Consequently, a composite figure was created from frames at different times in order to facilitate the annotation of GCPs.

\subsection{Test 2: Drone, nadir view}

In the case of test 2 , the fact of having a clear nadir view of the complete plot considerably simplified image georegistration. Measurement of one ground distance between two GCPs sufficed to estimate the conversion between image and ground coordinates. No projective transformation was needed. A sample IR frame in which these GCPs can be observed is displayed in figure 2. The main difficulty during this test arose from the drone instability. The footage had some jitter that needed to be cancelled through image processing techniques. Furthermore, exportable data from this video sequence was not radiometric. Available pixel values did not correspond to brightness temperatures. This type of representation is common in industry.

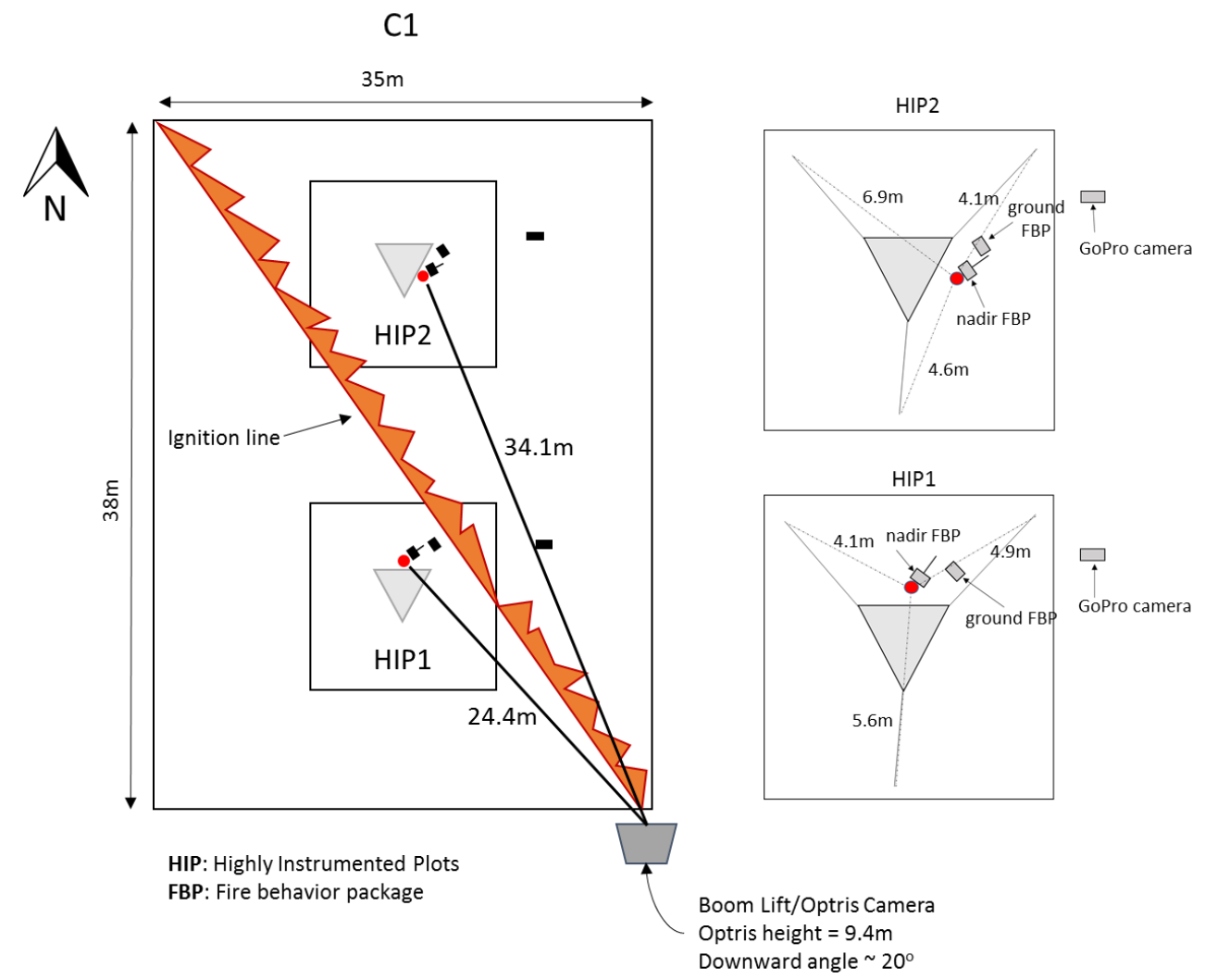

Figure 1 - Diagram of the item layout existing in test 1. All indicated distances are horizontal at ground level. 


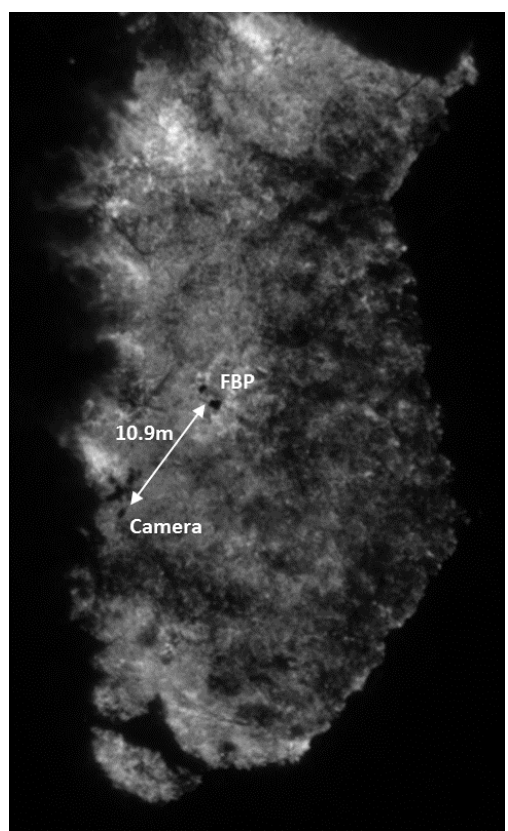

Figure 2 - Sample IR frame corresponding to test 2, with GCPs used for imagery geocorrection. FBP means Fire Behavior Package.

\section{Quantitative fire monitoring}

\subsection{Pre-processing modules}

By default, software provided by the manufacturer of camera 1 always stores acquired IR video in a private binary format. This format can only be read using the same manufacturer's software. IR video encapsulated this way can neither be exported to other formats. Moreover, data analysis tools officially provided by Optris are rather limited. To overcome these issues, we used the $\mathrm{C}++$ libraries provided by the manufacturer to build two small applications: one that directly operates the camera and stores radiometric data in a readable format, and another that retrieves thermal data from existing IR video. By using these applications, we could read and process high-frequency video containing actual brightness temperatures.

In the case of camera 2, manufacturer's software did allow exporting IR video in a standard format, but such video did not contain actual brightness temperatures. Frames could only be exported as JPEG images, valid for visualization but without radiometric information. Furthermore, this information was available with a low temporal resolution. Frame rate was close to $1 \mathrm{~Hz}$, but it was not kept constant. Greyscale frames could be used successfully to detect the fire perimeter evolution because our computer vision methods do not rely on precise radiometric data. However, timing was important to estimate rates of spread. Fortunately, the exact time at which each frame was originally acquired could be retrieved from each file's metadata. We used the open-source program Exiftool ${ }^{1}$ for this purpose.

In addition to format limitations, footage taken during both tests needed some degree of geometric correction. Imagery from test 1 was oblique and the corresponding $2 \mathrm{D}$ projective transformation between the camera plane and the ground was estimated using a set of Ground Control Points (GCPs). A composite image was created using different frames from the video sequence to simplify this task. Available GCPs were identified in this composite image and their location was used to estimate the

\footnotetext{
${ }^{1}$ Originally developed by Phil Harvey. Website: https://www.sno.phy.queensu.ca/ phil/exiftool/
} 
transformation between image and ground coordinates. Afterwards, this transformation was applied to all video frames.

Footage 2 did not need the application of a projective transformation because it was acquired from a nadir viewpoint. However, instabilities in the drone position translated into slight jitter in the video sequence. Light aircraft are usually susceptible to wind gusts, especially when they fly over an active fire. Although the DJI Zenmuse camera is specifically equipped with a mechanical stabilization system to minimize the impact of this, significant vibrations were present in the output video. This issue was resolved through additional video stabilization software, based on image registration and feature matching. Features are regions of pixels that can be described in terms of certain parameters. If those descriptors are invariant to translations, rotations and changes in scale, the same points can be detected in two consecutive video frames and their corresponding locations can be matched. This methodology was followed here to estimate the relative movement between each consecutive pair of frames. Once these movements were known, each frame was corrected and registered to the previous one. The final result was a stable footage.

\subsection{Computer vision algorithms for perimeter tracking}

Pre-processed IR imagery was used to follow the fire perimeter evolution and to measure its rate of spread. Both tasks were accomplished automatically using an adaptation of the algorithms described in Valero et al. (2018). The basis of these algorithms lie on edge detectors that search the highest brightness gradients within each image. Pixels are classified as edges or non-edges using two thresholds for the gradient magnitude. The correct thresholds are automatically estimated for each frame by the algorithm itself. Finding edges in the image allows the software to estimate the location of the fuel burning interface. If a time series is available, the evolution of the burning line can be reconstructed. Morphological operations are applied to derive an estimation of the burned perimeter location at each instant in time. Finally, the difference in fire perimeter positions between consecutive frames allows the computation of spatially-explicit rates of spread.

This methodology is not exempt of difficulties. The most significant detected so far consists in the rejection of ROS outliers. Actively burning lines usually exhibit flames whose length is not negligible. These flames must be avoided when detecting the fuel burning interface and computing ROS. Our edge detection algorithms are insensitive to flames up to a certain size, but the system becomes biased in the presence of regions with a high concentration of flames, especially if the same region keeps flaming for a long period of time. In these cases, unrealistic ROS values may be produced and they need to be detected and rejected. There are image processing techniques to achieve this by directly filtering flames out (Valero et al. 2017), but such methods are complex to implement and need considerable computational resources. Sometimes it is enough with the application of common statistical rules for outlier rejection. In this case, we applied the generalized extreme studentized deviate (GESD) test (Rosner 1983) to the ROS values obtained along each isochrone. This test is especially suitable for datasets that have multiple outliers but where the number of outliers is not known a priori.

\section{Results}

Once converted to a readable format, footage 1 provided reach radiometric data about test 1 , with a high temporal resolution $(27 \mathrm{~Hz}$ ). For its part, footage 2 had to be stabilized before becoming useful. Figure 3 exemplifies the video stabilization methodology based on feature matching. 


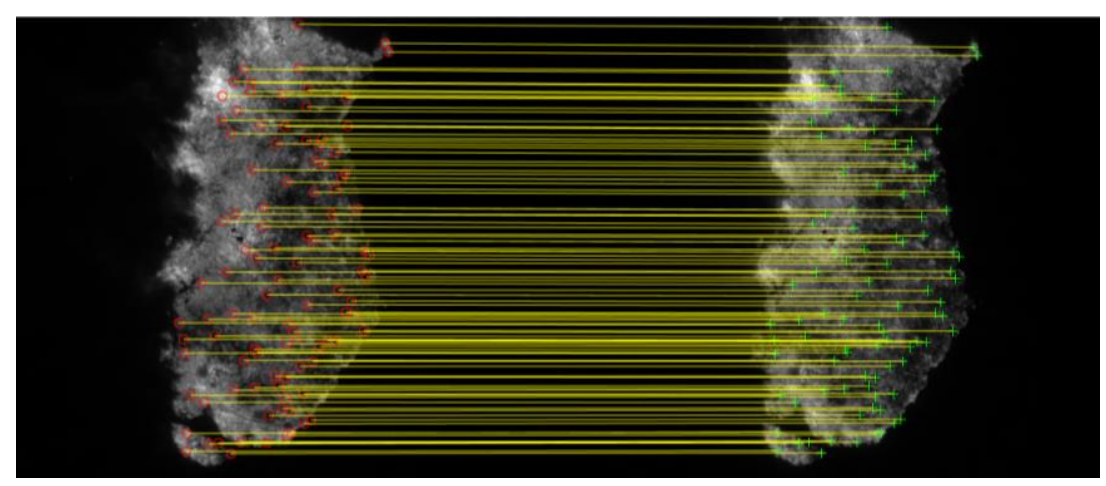

Figure 3 - Subset of matching features detected in two sample consecutive frames during the stabilization of the drone IR footage (test 2). Red and green points represent features. Yellow lines connect matched features. The relative movement between these two frames consisted of a translation of 13.74 pixel units and a scale change of $1.2 \%$.

After pre-processing, the perimeter tracking algorithms were applied to both video sequences at an approximate framerate of $1 \mathrm{~Hz}$. A subset of the obtained results is shown in figure 4 . Complete animated video with the detected perimeter evolution is available at the following links: https://goo.gl/bKb4Cu; https://goo.gl/47CxcU.
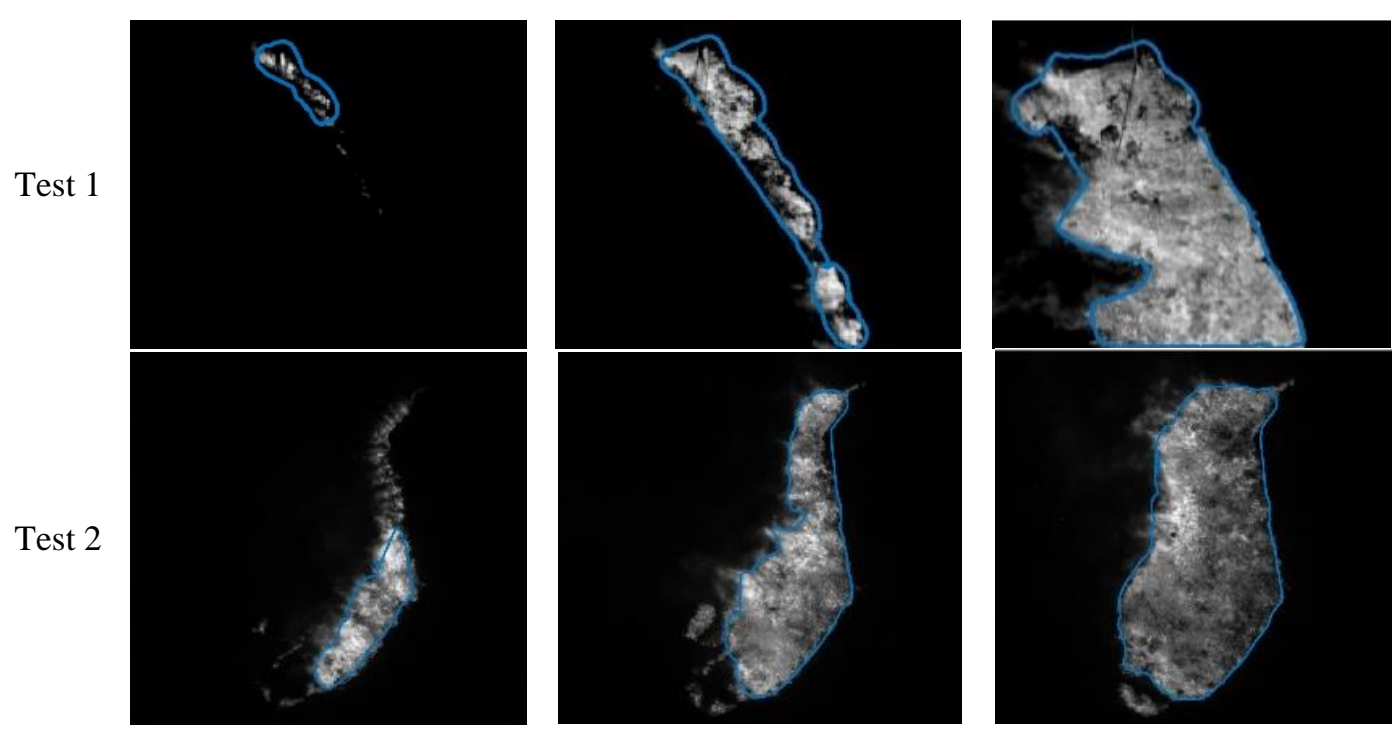

Figure 4 - Burning area automatically detected in TIR frames acquired by compact cameras. Displayed frames approximately correspond to footage beginning (left), midway (center) and end (right).

Finally, geocorrection information allowed the computation of ROS spatio-temporal distributions. Figure 5 summarizes this information. 

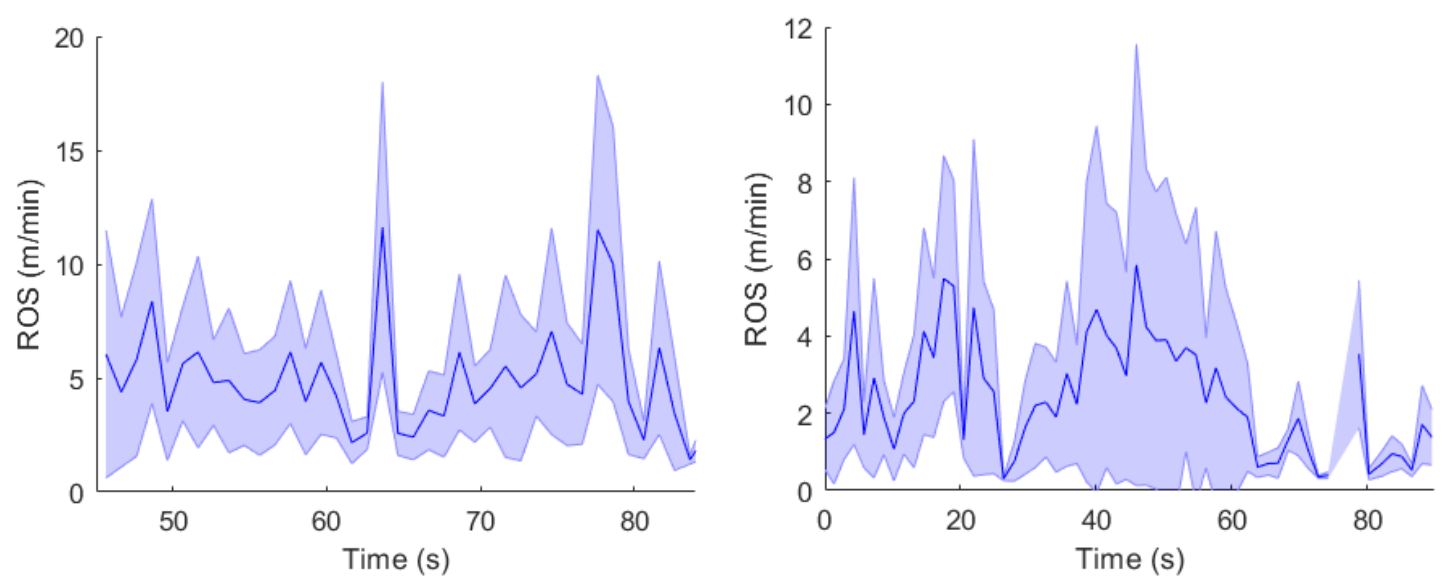

Figure 5 - Temporal evolution of remotely sensed rates of spread. Central solid line represents average values within each isochrone. Shaded area represents standard deviation within each isochrone. Left: test 1; right: test 2.

Rates of spread were not measured in situ, so values obtained remotely could not be compared with other experimental information. Nonetheless, results are in agreement with visual estimations. Moreover, the evolution of the detected fire perimeter represented in figure 4 and in the associated animated video is very similar to what a human operator would annotate manually.

\section{Discussion and conclusions}

The main goal of this paper was to assess the suitability of compact IR cameras for wildland fire monitoring. The camera models tested in this study as well as others have significant strengths for field deployment: they are light and easy to use, they consume little power and they are relatively affordable. However, they have certain limitations that need to be resolved. Some manufacturers enclose radiometric data into private formats, while their official software does not provide full processing capabilities. Furthermore, some recording configurations do not store actual brightness temperatures but just a visual representation of 'what is hot and what is cold'. Finally, one of the star applications of these cameras is their installation aboard RPAS, but small aircraft is highly susceptible to aerodynamic instabilities and video recorded from these platforms is usually shaky. A video stabilization step is often necessary before such imagery can be further processed.

This work proposes solutions for some of these issues, and the obtained results prove that data acquired with compact IR cameras has sufficient quality for a variety of wildfire applications: firstly, if an active fire is recorded from an overhead perspective, be it nadir or off-nadir, IR imagery can be processed to detect the location of the fuel burning interface and the fire perimeter at a certain time. Furthermore, if time series information is also available with sufficient frequency, rates of spread can be estimated remotely. This type of data may be useful for fire behavior research, but it may also have a relevant utility at operational level. Emergency responders could benefit from updated quantitative information about the state of the fire during an incident. Moreover, wildfire monitoring software can be integrated into broader decision support systems that combine fire information with fuel, terrain and weather data. Such systems may even include data-driven fire spread simulators which, if timely fed accurate fire observations, are able to deliver reliable forecasts of the fire evolution in the short term.

Key aspects to be addressed in the future relate to imagery geocorrection and the communication infrastructure. Georeferencing IR aerial imagery is the only step that remains manual in the image processing workflow. Its automation would allow the achievement of a totally autonomous fire monitoring system. On the other hand, extracted information will only be useful at operational level if it can be reliably transmitted from the aircraft to a command center in near real time. This requires 
important hardware developments such as on-board data processing architectures and deployable communication networks.

\section{Acknowledgements}

This research was partially funded by the Spanish Ministry of Economy and Competitiveness (projects CTM2014-57448-R and CTQ2017-85990-R, co-financed with FEDER funds) and the Spanish Ministry of Education, Culture and Sport (FPU Programme). The IR data was acquired using hardware from the University of Montana, National Center for Landscape Fire Analysis.

\section{References}

Butler B, Teske C, Jimenez D, O’Brien J, Sopko P, Wold C, Vosburgh M, Hornsby B, Loudermilk E (2016) Observations of energy transport and rate of spreads from low-intensity fires in longleaf pine habitat - RxCADRE 2012. International Journal of Wildland Fire 25, 76-89. doi:10.1071/WF14154.

Clements CB, Davis B, Seto D, Contezac J, Kochanski A, Fillipi J-B, Lareau N, Barboni B, Butler B, Krueger S, Ottmar R, Vihnanek R, Heilman E, Flynn J, Jenkins M, Mandel J, Teske C, Jimenez D, O'Brien J, Lefer B (2014) Overview of the 2013 FireFlux II grass fire field experiment. 'Adv. For. fire Res. - Proc. 7th Int. Conf. For. Fire Res.' pp. 392-400 doi:10.14195/978-989-26-0884-6_43.

Clements CB, Zhong S, Goodrick S, Li J, Potter BE, Bian X, Heilman WE, Charney JJ, Perna R, Jang M, Lee D, Patel M, Street S, Aumann G (2007) Observing the Dynamics of Wildland Grass Fires: FireFlux - A Field Validation Experiment. Bulletin of the American Meteorological Society 88, 1369-1382. doi:10.1175/BAMS-88-9-1369.

Cruz MG, Alexander ME (2013) Uncertainty associated with model predictions of surface and crown fire rates of spread. Environmental Modelling and Software 47, 16-28. doi:10.1016/j.envsoft.2013.04.004.

Cruz MG, Matthews S, Gould J, Ellis P (2010) Fire dynamics in mallee-heath: fuel, weather and fire behaviour prediction in south Australian semi-arid shrublands. Bushfire Cooperative Research Centre, Technical Report A1001. http://www.bushfirecrc.com/sites/default/files/firedynamicsinmalleeheathreport.pdf.

Dickinson MB, Hudak AT, Zajkowski T, Loudermilk EL, Schroeder W, Ellison L, Kremens RL, Holley W, Martinez O, Paxton A, Bright BC, O’Brien JJ, Hornsby B, Ichoku C, Faulring J, Gerace A, Peterson D, Mauceri J (2016) Measuring radiant emissions from entire prescribed fires with ground, airborne and satellite sensors - RxCADRE 2012. International Journal of Wildland Fire 25, 48-61. doi:10.1071/WF15090.

Johnston JM, Wooster MJ, Paugam R, Wang X, Lynham TJ, Johnston LM (2017) Direct estimation of Byram's fire intensity from infrared remote sensing imagery. International Journal of Wildland Fire 26, 668-684. doi:http://dx.doi.org/10.1071/WF16178.

Mandel J, Bennethum LS, Beezley JD, Coen JL, Douglas CC, Kim M, Vodacek A (2008) A wildland fire model with data assimilation. Mathematics and Computers in Simulation 79, 584-606. doi:10.1016/j.matcom.2008.03.015.

McAllister S, Finney M (2017) Autoignition of wood under combined convective and radiative heating. Proceedings of the Combustion Institute 36, 3073-3080. doi:10.1016/j.proci.2016.06.110.

Miller C, Finney MA, McAllister S, Sluder E, Gollner MJ (2017) Investigating coherent streaks in wildfires via heated plates in crosswind. Fire Safety Journal 91, 735-741. doi:10.1016/j.firesaf.2017.03.035. 
O’Brien JJ, Loudermilk EL, Hornsby B, Hudak AT, Bright BC, Dickinson MB, Hiers JK, Teske C, Ottmar RD (2016) High-resolution infrared thermography for capturing wildland fire behaviour: RxCADRE 2012. International Journal of Wildland Fire 25, 62-75. doi:10.1071/WF14165.

Ottmar RD, Hiers JK, Butler BW, Clements CB, Dickinson MB, Hudak AT, O'Brien JJ, Potter BE, Rowell EM, Strand TM (2016) Measurements, datasets and preliminary results from the RxCADRE project-2008, 2011 and 2012. International Journal of Wildland Fire 25, 1-9.

Paugam R, Wooster MJ, Roberts G (2013) Use of Handheld Thermal Imager Data for Airborne Mapping of Fire Radiative Power and Energy and Flame Front Rate of Spread. IEEE Transactions on Geoscience and Remote Sensing 51, 3385-3399. doi:10.1109/TGRS.2012.2220368.

Pérez Y, Pastor E, Planas E, Plucinski M, Gould J (2011) Computing forest fires aerial suppression effectiveness by IR monitoring. Fire Safety Journal 46, 2-8. doi:10.1016/j.firesaf.2010.06.004.

Plucinski M, Pastor E (2013) Criteria and methodology for evaluating aerial wildfire suppression. International Journal of Wildland Fire 22, 1144-1154. doi:10.1071/WF13040.

Rios O, Jahn W, Rein G (2014) Forecasting wind-driven wildfires using an inverse modelling approach. Natural Hazards and Earth System Sciences 14, 1491-1503. doi:10.5194/nhess-141491-2014.

Rios O, Pastor E, Valero MM, Planas E (2016) Short-term fire front spread prediction using inverse modelling and airborne infrared images. International Journal of Wildland Fire 25, 1033-1047. doi:10.1071/WF16031.

Rochoux MC, Emery C, Ricci S, Cuenot B, Trouvé A (2015) Towards predictive data-driven simulations of wildfire spread - Part II: Ensemble Kalman Filter for the state estimation of a fronttracking simulator of wildfire spread. Natural Hazards and Earth System Sciences 15, 1721-1739. doi:doi:10.5194/nhess-15-1721-2015.

Rochoux MC, Ricci S, Lucor D, Cuenot B, Trouvé A (2014) Towards predictive data-driven simulations of wildfire spread - Part I: Reduced-cost ensemble Kalman filter based on a polynomial chaos surrogate model for parameter estimation. Natural Hazards and Earth System Sciences 14, 2951-2973. doi:10.5194/nhess-14-2951-2014.

Rosner B (1983) Percentage Points for a Generalized ESD Many-Outlier Procedure. Technometrics 25, 165-172. doi:10.1080/00401706.1983.10487848.

Stow DA, Riggan PJ, Storey EJ, Coulter LL (2014) Measuring fire spread rates from repeat pass airborne thermal infrared imagery. Remote Sensing Letters 5, 803-812. doi:10.1080/2150704X.2014.967882.

Valero MM, Rios O, Pastor E, Planas E (2018) Automated location of active fire perimeters in aerial infrared imaging using unsupervised edge detectors. International Journal of Wildland Fire 27, 241-256. doi:10.1071/WF17093.

Valero MM, Verstockt S, Rios O, Pastor E, Vandecasteele F, Planas E (2017) Flame filtering and perimeter localization of wildfires using aerial thermal imagery. In 'Proc. SPIE 10214. Thermosense Therm. Infrared Appl. XXXIX', doi:10.1117/12.2262100.

Zajkowski TJ, Dickinson MB, Hiers JK, Holley W, Williams BW, Paxton A, Martinez O, Walker GW (2016) Evaluation and use of remotely piloted aircraft systems for operations and research RxCADRE 2012. International Journal of Wildland Fire 25, 114-128. doi:10.1071/WF14176. 